\title{
EFEITO DA EMBALAGEM E TEMPERATURA DE ARMAZENAMENTO EM REPOLHO MINIMAMENTE PROCESSADO
}

\author{
Maria Madalena RINALDI , Benedito Carlos BENEDETTI", Luciana CALORE²
}

\begin{abstract}
RESUMO
O objetivo deste trabalho foi avaliar as alterações no repolho minimamente processado quando armazenado em diferentes embalagens e temperaturas. O processamento mínimo consistiu em seleção, classificação e resfriamento da matéria-prima, seguido do processo de corte em tiras, enxágüe em água tratada para a remoção dos exudados celulares, sanitização em solução com $150 \mathrm{mgL}$ de cloro ativo, enxágüe, centrifugação, pesagem, acondicionamento em bandejas de poliestireno expandido, revestidas com filme flexivel de policloreto de vinila (PVC), $12 \mu \mathrm{m}$, e embalagens de tereftalato de polietileno (PET), e armazenamento por 15 dias em temperaturas de 0,5 e $10^{\circ} \mathrm{C}$. A cada três dias avaliou-se a concentração de $\mathrm{O}$ e $\mathrm{CO}$ na atmosfera interna das embal agens, bem como o $\mathrm{pH}$, acidez titulável, sólidos solúveis e vitamina $\mathrm{C}$ no repolho minimamente processado. Concluiu-se que o repolho acondicionado na embalagem PVC apresentou menor perda de vitamina C durante os 15 dias de armazenamento nas três temperaturas. Esta embalagem também apresentou maior concentração de $\mathrm{CO}_{z}$ e menor de $\mathrm{O}_{z}$, porém dentro dos níveis aceitáveis, garantindo assim maior vida útil ao repolho minimamente processado. Observou-se que não houve diferença significativa na vida útil do produto armazenado em temperaturas de 0 e $5^{\circ} \mathrm{C}$, nas duas embalagens avaliadas, porém a $10^{\circ} \mathrm{C}$ a mesma reduziu-se significativamente, ao nivel de $5 \%$ de probabilidade.
\end{abstract}

Palavras-chave: processamento mínimo; atmosfera modificada; conservação; Brassica oleracea var. capitata.

\section{SUMMARY}

MINIMALLY PROCESSED CABBAGE: EFFECTS OF PACKAGING AND STORAGE TEMPERATURE. The objective of this work was to evaluate the changes in the minimally processed cabbage when stored in different packages and temperatures. The minimum process consisted of selection, classification and refrigeration of the raw material, followed by cutting in slices, rinsed with treated tap water for the elimination of cellular exudates, sanitization in solutions with $150 \mathrm{mgL}$ of active chlorine, rinsing, centrifugation, weighing, conditioning in polystyrene expanded trays covered with polyvinyl chloride (PVC), $12 \mu \mathrm{m}$, and polyethylene terephtalate (PET) packages and stored for 15 days at 0,5 and $10^{\circ} \mathrm{C}$ temperatures. Every three days the following analyses where carried out: $\mathrm{O}$ and $\mathrm{CO}_{2}$ concentrations inside the packages, $\mathrm{pH}$, tritatable acidity, soluble solids and vitamin $\mathrm{C}$ in the minimally processed cabbage. It was concluded that the cabbage conditioned in the PVC packages presented lower vitamin $\mathrm{C}$ loss during the 15 days of storage at all temperatures. These packages also presented higher concentrations of $\mathrm{CO}_{2}$ and lower of $\mathrm{O}_{2}$, although within the acceptable levels, guaranteeing larger shelf life to the minimally processed cabbage. The shelf life for the products stored at 0 and $5^{\circ} \mathrm{C}$ were statistically similar; however at $10^{\circ} \mathrm{C}$, it was reduced appreciably, at the level of $5 \%$ of probability

Keywords: minimum processing; modified atmosphere; conservation; Brassica oleracea var. capitata.

\section{1 - INTRODUÇÃO}

Os produtos minimamente processados devem ser armazenados em temperatura adequada, sendo este o fator mais importante no retardamento da perda de umidade, na alteração da composição da atmosfera ao redor do produto, na perda das características nutricionais, na minimização da contaminação microbiológica, bem como, na manutenção da qualidade sensorial dos mesmos. Portanto, é essencial que estes produtos sejam mantidos em refrigeração, a fim de prover a manutenção e prolongamento do tempo de estocagem, minimizando as injúrias provocadas pelo processamento [4, 21, 24, 28]. A temperatura próxima a $0^{\circ} \mathrm{C}$ é considerada ideal para o armazenamento de hortaliças folhosas [15]. Os produtos minimamente processados geralmente são mais perecíveis que os que lhes deram origem e, por isso, devem ser mantidos a baixas temperaturas, sendo $0^{\circ} \mathrm{C}$ considerada

Recebido para publicação em 17/05/2004. Aceito para publicação em 25/07/2005(001346).

Faculdade de Engenharia Agrícola, Universidade Estadual de Campinas (FEAGRI/UNICAMP). Endereço: Cidade Universitária "Zeferino Vaz", CP: 6011, CEP: 13083-970, Campinas, SP. Telefone: (19) 3788-1075.E-mail:benedeti@agr.unicamp.br/mrinaldi@bol.com.br A quem a correspondência deve ser enviada. ideal. Entretanto, mas por razões econômicas, são utilizadas temperaturas ao redor de 5 a $10^{\circ} \mathrm{C}$, acelerando assim o processo de deterioração dos mesmos [25].

Além da redução da temperatura a níveis adequados, a manipulação da concentração de gases na atmosfera, a qual está submetido o produto vegetal, é uma das maneiras mais eficazes na redução de sua atividade respiratória e aumento de sua vida pós-colheita. O envolvimento de frutos e hortaliças em simples embalagens plásticas, ou em sofisticados filmes poliméricos, é uma maneira simples de manipular a atmosfera ao seu redor $[7$, 23]. Dentre os materiais de embalagens disponiveis, o polietileno tereftalato (PET) tem sido um dos polímeros mais utilizados. Devido as suas excelentes características fisico-mecânicas, pode ser aplicado como embalagem a inúmeros produtos alimentícios, quer na forma de garrafas, como na forma de filmes que podem ser simples, ou co-extrusados com outros polimeros, ou ainda, na forma de bandejas laminadas com papel cartão [11]. Existem várias formulações de policloreto de vinila (PVC) que são utilizadas na produção de filmes. Os filmes de PVC apresentam uma taxa de permeabilidade ao vapor de água moderada e podem apresentar altas taxas de permeabilidade ao oxigênio e dióxido de carbono, o que permite sua utilização em embalagens para produtos minimamente processados [23]. 
O objetivo deste trabalho foi avaliar o comportamento do repolho (Brassica oleracea var. capitata) minimamente processado, acondicionado em embalagens de poliestireno expandido, revestidas com filme flexivel de policloreto de vinila (PVC), $12 \mu \mathrm{m}$, e embalagens plásticas de tereftalato de polietileno (PET), armazenadas nas temperaturas de 0,5 e $10^{\circ} \mathrm{C}$.

\section{2 - MATERIAL E MÉTODOS}

Utilizou-se repolho da variedade Sagitarius, obtido de uma plantação comercial localizada no municipio de Morungaba, SP. No momento da colheita, realizada nas primeiras horas do dia, as cabeças de repolho encontravam-se no ponto ótimo de maturidade hortícola, ou seja, completamente formadas e desenvolvidas, apresentando-se compactas e com as folhas bem imbricadas e com idade média de 90 dias de campo. Imediatamente após a colheita, a matéria-prima foi transportada ao laboratório onde foi selecionada, descartando-se as cabeças mal formadas, folhas externas (superficiais), operação conhecida como toalete do produto, e as que apresentavam qualquer indício de dano proveniente do ataque de pragas e doenças. A seguir, as cabeças foram lavadas em água corrente, colocadas em engradados plásticos previamente higienizados, resfriadas em câmara fria a temperatura de $10 \pm 1^{\circ} \mathrm{C}$, até o produto atingir essa temperatura no interior das cabeças, e $95 \pm 5 \%$ de umidade relativa, sendo em seguida submetidas ao processamento minimo.

Devido à importância de baixas temperaturas na conservação da qualidade dos produtos hortícolas, principalmente minimamente processados, a temperatura da água de lavagem, sanitização e enxágües foi mantida a 5 $\pm 2{ }^{\circ} \mathrm{C}$, sendo controlada com a adição de gelo à mesma, quando necessário. Para garantir a sanidade do repolho minimamente processado, as Boas Práticas de Fabricação foram observadas, ou seja, a área de processamento foi previamente higienizada, bem como todos os utensílios mantidos em seu interior. A temperatura do ambiente foi mantida a $15 \pm 3^{\circ} \mathrm{C}$ e todas as pessoas envolvidas no processamento utilizaram Equipamento de Proteção Individual (EPI), que constou de avental, touca, máscara e luvas.

O processamento mínimo consistiu em corte manual das cabeças de repolho em quatro partes, com o auxílio de facas afiadas, retirando-se as partes internas (talos) não utilizadas no processamento minimo; fatiamento em tiras com espessura de $\pm 3 \mathrm{~mm}$, em processador de alimentos marca Skymsen, tipo PA-7L, fabricado pela metalúrgica Siemsen Ltda; enxágüe por $3 \mathrm{~min}$ em água tratada (própria para o consumo), para a remoção dos exudados celulares liberados pelo processo de corte das células; imersão por $10 \mathrm{~min}$ em solução sanitizante de hipoclorito de sódio com 150mg.L de cloro ativo, com o objetivo de reduzir a carga microbiana; enxágüe por $5 \mathrm{~min}$ com solução de $5 \mathrm{mg}$.L do mesmo sanitizante, para retirar o excesso de cloro da etapa anterior; e centrifugação por $5 \mathrm{~min}$ em centrífuga doméstica marca ARNO com velo- cidade angular média de 2200rpm onde, de acordo com informações do fabricante, seria equivalente a $800 \mathrm{~g}$, com o objetivo de remover o excesso de água obtido durante a sanitização e enxágües. Em seguida, $250 \mathrm{~g}$ do produto processado foram acondicionadas em bandejas $(210 \mathrm{x}$ $140 \times 20 \mathrm{~mm}$ ) de poliestireno expandido, que foram revestidas com filme flexivel de policloreto de vinila (PVC), $12 \mu \mathrm{m}$, tipo OMNI-AM, fabricado pela Goodyear, e em embalagens plásticas (190 x $120 \times 60 \mathrm{~mm})$ de tereftalato de polietileno (PET), com tampa acoplada e sem perfurações, tipo P-27, fabricada pela Montplas. As embalagens foram armazenadas em câmaras frias nas temperaturas de 0,5 e $10^{\circ} \mathrm{C}$ por um período de 15 dias. A cada três dias foram realizadas análises da concentração de $\mathrm{O}_{2}$ e $\mathrm{CO}_{2}$ na atmosfera interna das embalagens, bem como $\mathrm{pH}$, acidez titulável, sólidos solúveis e vitamina $\mathrm{C}$ no repolho minimamente processado.

As temperaturas de 0 e $5^{\circ} \mathrm{C}$ utilizadas no armazenamento, representam as condições ótimas recomendadas para o armazenamento do repolho inteiro e minimamente processado, e $10^{\circ} \mathrm{C}$ às condições de temperatura geralmente encontradas nas gôndolas dos supermercados, onde o produto fica exposto para a venda aos possiveis consumidores.

Os resultados foram avaliados estatisticamente por meio do delineamento inteiramente casualizado, com três repetições para cada tratamento (duas embalagens e três temperaturas), onde cada repetição consistiu em uma embalagem contendo $250 \mathrm{~g}$ de repolho minimamente processado. Na análise de variância, as médias foram comparadas pelo teste Tukey ao nivel de $5 \%$ de probabilidade, com o auxílio do software ESTAT Sistema para Análise Estatística UNESP, Campus Jaboticabal.

A composição gasosa na atmosfera interna das embalagens e as análises químicas na solução obtida pela extrusão de tiras de repolho minimamente processado em centrífuga doméstica, foram realizadas da seguinte forma:

- Concentração de oxigênio e dióxido de carbono: Determinada em analisador de gás (Head Space Analyser, MOCON). Este método de determinação consiste na leitura direta em porcentagem de $\mathrm{O}_{2}$ e $\mathrm{CO}_{2}$ através da introdução de uma seringa hermética própria do aparelho, através de um septo de silicone colocado nas embalagens.

- $\quad \mathrm{pH}$ : Determinado pelo uso de pHmetro digital. O método é baseado na determinação hidrogeniônica $(\mathrm{pH})$ utilizando-se o potenciômetro, conforme procedimento descrito por CARVALHO et al. [5].

- Acidez titulável: O método para a avaliação da acidez foi o descrito pelo INSTITUTO ADOLFO LUTZ [12] utilizando-se pHmetro. Pesou-se $10 \mathrm{~g}$ da amostra em um béquer e adicionou-se $90 \mathrm{~mL}$ de água destilada. Titulou-se com solução de hidróxido de sódio $0,100 \mathrm{~N}$ até o $\mathrm{pH}$ atingir 8,1. Os resultados foram expressos em porcentagem de ácido cítrico, ou seja, gramas de 
ácido cítrico/ 100 gramas de amostra do produto (repolho).

- Sólidos Solúveis (SS): Realizado segundo BOLIN \& HUXSOLL [3] onde fez-se a leitura da solução utilizando-se o refratômetro manual. Os resultados foram expressos em ${ }^{\circ}$ Brix.

- Vitamina C: Determinada segundo metodologia de CARVALHO et al. [5] a qual se baseia na redução do indicador 2,6-diclorobenzenoindofenol (DCFI) pelo ácido ascórbico, sendo expresso como mg ácido ascórbico/100g de produto.

\section{3 - RESULTADOS E DISCUSSÃO}

As embalagens PVC e PET apresentaram diferenças significativas em relação à concentração de $\mathrm{O}_{2}$ (Figura 1a) e $\mathrm{CO}_{2}$ (Figura 1b) medidas em seus interiores. A embalagem PVC apresentou maior porcentagem de $\mathrm{CO}_{2}$ e menor de $\mathrm{O}_{2}$ em relação à embalagem PET, a qual não demonstrou variação significativa nestes gases ao longo dos 15 dias de armazenamento, apesar de no $15^{\circ}$ dia, a mesma apresentar diminuição na concentração de $\mathrm{O}_{2}$ e aumento na concentração de $\mathrm{CO}_{2}$, nas temperaturas de 5 e $10^{\circ} \mathrm{C}$, igualando-se às concentrações apresentadas pela embalagem de PVC nas mesmas temperaturas.

A menor concentração de $\mathrm{O}_{2}$ e maior de $\mathrm{CO}_{2}$ durante todo o experimento, foi observada na embalagem PVC no $3^{\circ}$ dia de armazenamento atingindo $3,5 \%$ de $\mathrm{CO}_{2}$ a $10^{\circ} \mathrm{C}$, não sendo estatisticamente diferente, ao nivel de $5 \%$ de probabilidade, das demais temperaturas estudadas na mesma embalagem. Houve diferença significativa entre as embalagens do $3^{\circ}$ ao $12^{\circ}$ dias de armazenamento nas três temperaturas. Com exceção do $15^{\circ}$ dia, a embalagem de PVC sempre apresentou menor porcentagem de $\mathrm{O}_{2}$, sendo a maior redução ocorrida entre o processamento e o $3^{\text {o }}$ dia de armazenamento, diminuindo de 20,5 para $12,0 \%$ na temperatura de $10^{\circ} \mathrm{C}$. No entanto, a partir do $6^{\circ}$ dia não ocorreu variação significativa na concentração deste gás, oscilando entre 16,0 e 18,5\%, mantendo níveis abaixo da concentração atmosférica, sendo que na temperatura de $0^{\circ} \mathrm{C}$, ocorreu uma tendência de equilíbrio na concentração de $\mathrm{O}_{2}$ do $9^{\circ}$ ao $15^{\circ}$ dia de armazenamento.

As concentrações dos gases $\left(\mathrm{O}_{2}\right.$ e $\left.\mathrm{CO}_{2}\right)$ no interior das embalagens PVC foram inversamente proporcionais, sugerindo que o fator responsável pelo aumento do $\mathrm{CO}_{2}$ e diminuição do $\mathrm{O}_{2}$ pode ter sido a atividade respiratória do produto e a permeabilidade dessa embalagem. A embalagem PET apresentou hermeticidade inadequada no sistema de fechamento, sendo que, pelas características já conhecidas quanto à permeabilidade deste polímero ao $\mathrm{O}_{2}$ e $\mathrm{CO}_{2}$, provavelmente, a concentração de $\mathrm{O}_{2}$ teria sido inferior, e a concentração de $\mathrm{CO}_{\text {s }}$ superior às apresentadas pela embalagem PVC, $12 \mu \mathrm{m}$. Esta afirmação pode ser justificada com dados apresentados em estudos com goiaba minimamente processada e osmoticamente desidratada, onde PEREIRA [20] também observou hermeticidade inadequada das embalagens PET utilizadas, apesar da mesma ter garantido vida útil de 24 dias ao produto. Concluiu-se, ainda, que apesar da embalagem PVC ter mantido niveis de $\mathrm{O}_{2}$ abaixo de $20,5 \%$, não foi suficiente para afirmar que houve uma redução significativa na taxa respiratória deste produto, pois segundo WILLS et al. [30], a concentração de $\mathrm{O}_{2}$ no meio deve ser menor que $10 \%$ para reduzir significativamente a taxa respiratória de produtos minimamente processados. Devido a isso, não se pode afirmar que essa embalagem, apesar de ser citada como uma das mais comercialmente utilizadas para hortaliças minimamente processadas, seja adequada quanto à permeabilidade $\mathrm{ao}_{2} \mathrm{O}^{\mathrm{CO}}$ para o acondicionamento de repolho minimamente processado pois, segundo CRISOSTO, MITCHAM \& KADER [8], KADER [14] e SUSLOW \& CANTWELL [29], a concentração de $\mathrm{O}_{2} \mathrm{e}$ $\mathrm{CO}_{2}$ adequadas para o armazenamento do repolho é de 35\% e 3-7\%, respectivamente.

$\mathrm{O} \mathrm{pH}$ apresentou valor inicial de 5,85 chegando a um máximo de 6,20 no $3^{\circ}$ dia de armazenamento, na embalagem de PVC a $10^{\circ} \mathrm{C}$ (Figura 2a). Segundo a classificação de CHITARRA \& CHITARRA [6], este produto é não ácido.
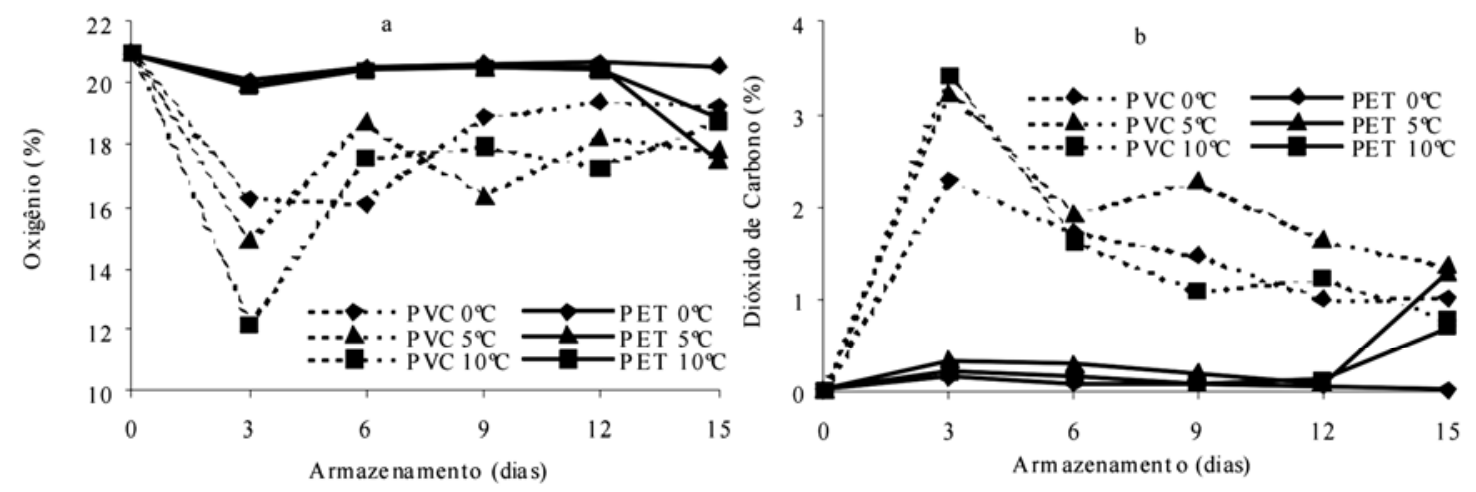

FIGURA 1 - Concentrações de oxigênio (a) e dióxido de carbono (b) durante o armazenamento de repolho minimamente processado 
O produto na embalagem PVC apresentou valores de $\mathrm{pH}$ significativamente maiores que na embalagem PET, entre o $3^{\circ}$ e $12^{\circ}$ dias de armazenamento. Este resultado está em desacordo com o obtido por SILVA [27], que não encontrou efeito significativo no $\mathrm{pH}$ em repolhos minimamente processados, embalados em filmes de polietileno, de baixa e alta densidade, e polipropileno, armazenados por 15 dias na temperatura de $5^{\circ} \mathrm{C}$. Segundo este autor, o $\mathrm{pH}$ variou muito pouco com o tempo, apresentando um pequeno aumento, nas três embalagens estudadas. Em relação à temperatura, não houve diferença significativa nos valores de $\mathrm{pH}$ entre 0 e $5^{\circ} \mathrm{C}$, diferindo de $10^{\circ} \mathrm{C}$ que apresentou maiores valores no $3^{\circ}, 6^{\circ}, 12^{\circ}$ e $15^{\circ}$ dia de armazenamento para as duas embalagens estudadas. A tendência de aumento de $\mathrm{pH}$ observada em algumas temperaturas, periodos e embalagens (Figura 2a), apesar de nem todos serem estatisticamente significativos, ao nível de $5 \%$ de probabilidade, pode ser explicado segundo KADER [13] pela resposta do tecido ao neutralizar a acidez gerada pelo $\mathrm{CO}_{2}$ ou ao aumento da população de microrganismos [19]. Quanto a última afirmação, nada se pode concluir, pois não foram realizadas análises microbiológicas no produto estudado.

De maneira geral, para todos os tratamentos, ocorreu redução na acidez até o $9^{0}$ dia de armazenamento, com aumento no $12^{\mathrm{o}}$ e nova redução até o final (Figura 2b). A maior variação ocorreu entre o $9^{\circ}$ e $12^{\circ}$ dias, aproximando-se dos valores obtidos inicialmente. Pode-se observar que o repolho acondicionado na embalagem PVC apresentou maior acidez que o acondicionado na embalagem PET. Com relação à temperatura, para as duas embalagens, o repolho armazenado a $0^{\circ} \mathrm{C}$ apresentou maior acidez que o armazenado a 5 e $10^{\circ} \mathrm{C}$.

Esse comportamento de redução da acidez corresponde ao que acontece geralmente com produtos vege- tais colhidos, como exemplo alface e pimentão [2, 9], com exceção para algumas frutas de caroço, como pêssegos, ameixas e nectarinas, que apresentam aumento na acidez após a colheita, correlacionando-se com a geração de radicais ácidos na parede celular [1]. Segundo ROURA, DAVIDOVICH \& DEL VALLE [22], logo após o processamento mínimo, o tecido vegetal apresenta uma respiração maior, levando a um decréscimo acentuado da acidez no início do armazenamento, devido ao consumo dos ácidos orgânicos (substâncias de reserva) no processo respiratório.

De acordo com CHITARRA \& CHITARRA [6] o teor de ácidos orgânicos diminui com a maturação das frutas, em decorrência do processo respiratório ou de sua conversão em açúcares, sendo que, em alguns casos, há um pequeno aumento nos valores com o aumento da maturação. A diminuição da acidez em produtos vegetais pode ser justificada pelo consumo do próprio vegetal, na tentativa de se manter em seu estado inicial. KAYS [16] também afirma que, após a colheita e durante o armazenamento, a concentração total de ácidos orgânicos tende a diminuir, sendo que as mudanças pós-colheita variam com a espécie de ácido em questão, tipo de tecido, manejo e condições de armazenamento, cultivar, ano de produção e diversos outros parâmetros.

Dessa forma, pode-se concluir que a diminuição na acidez deve-se, provavelmente, à atividade metabólica mais acentuada no repolho acondicionado na embalagem PET induzindo maior consumo de ácidos orgânicos e radicais ácidos da parede celular pois, segundo FERRI [10] o decréscimo na acidez pode em parte ser explicado pelo consumo de moléculas ácidas, em especial os ácidos orgânicos no processo de respiração. Quanto ao pequeno aumento na acidez apresentado no $12^{\circ}$ dia de armazenamento em todos os tratamentos, menos acentuado na embalagem PVC na temperatura de $5^{\circ} \mathrm{C}$, não foram encon-
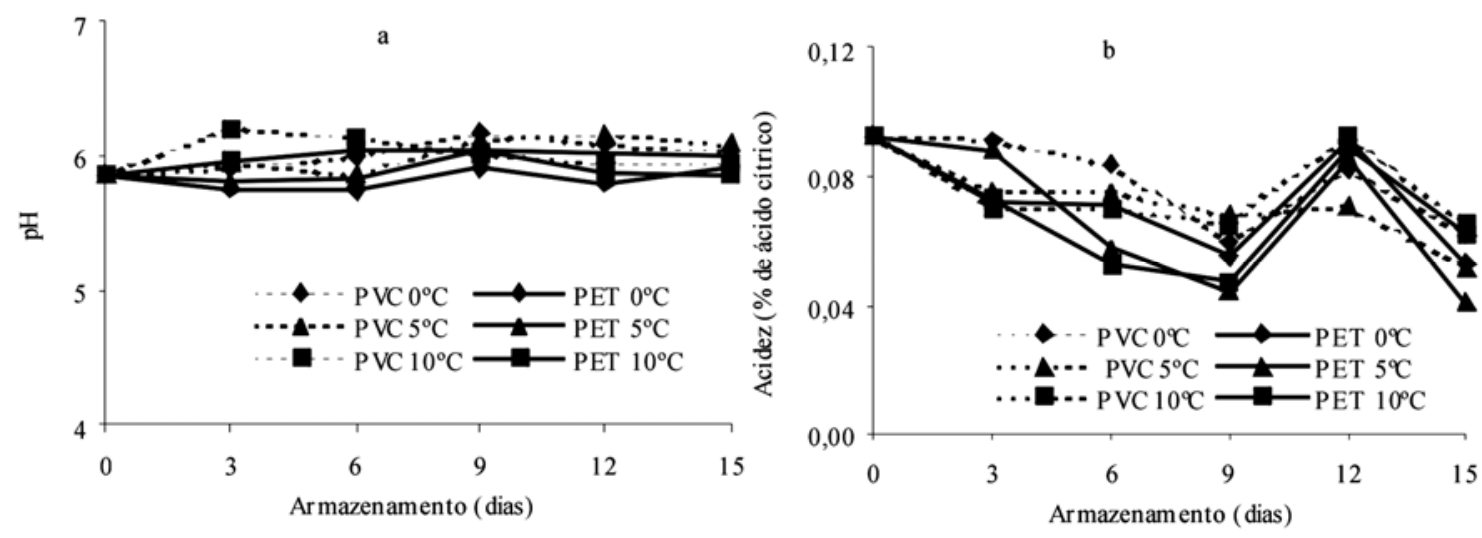

FIGURA 2 - Valores de pH (a) e acidez titulável (b) durante o armazenamento de repolho minimamente processado 
tradas referências que expliquem uma redução e posterior aumento da acidez em repolhos durante o armazenamento. De acordo com SENTER et al. [26], o aumento na acidez de produtos armazenados por curtos períodos pode ser explicado pela geração de radicais (ácidos galacturônicos) a partir da hidrólise dos constituintes da parede celular, em especial, as pectinas.

Os sólidos solúveis apresentaram comportamento semelhante para todas as temperaturas e embalagens com valor inicial médio, logo após o processamento, de $4,9^{\circ}$ Brix (Figura 3a). Observou-se uma redução significativa dos sólidos solúveis até o 9ํ dia de armazenamento, com exceção da embalagem $\mathrm{PVC}$ a $0^{\circ} \mathrm{C}$ onde ocorreu um aumento do $3^{\circ}$ para o $6^{-}$dia. No $12^{\circ}$ dia, o produto apresentou acréscimo nos valores obtidos para este parâmetro, não sendo estatisticamente diferente do obtido no início do experimento, seguido de redução até o $15^{\circ}$ nas duas embalagens estudadas, sendo semelhante ao comportamento da acidez durante todo o período. A redução dos sólidos solúveis pode ter sido influenciada pelo aumento da taxa respiratória do produto, utilizando as reservas existentes nas células, e o aumento ocorrido no $12^{\circ}$ dia de armazenamento, possivelmente devido a reações bioquímicas na parede celular, ou à possivel perda de massa (parâmetro não analisado neste experimento) ao longo da armazenagem e conseqüente aumento na concentração dos ácidos.

Durante o armazenamento, o repolho acondicionado na embalagem PVC apresentou teores de sólidos solúveis superiores ou iguais ao acondicionado na embalagem $\mathrm{PET}$, nas três temperaturas, sendo que, a $0^{\circ} \mathrm{C}$ ocorreu maior estabilidade no armazenamento do repolho minimamente processado. Os valores de sólidos solúveis ( $F i-$ gura 3a) mostram que as duas embalagens utilizadas não foram suficientes na modificação da atmosfera para garantir menor consumo de substrato do produto. Este comportamento contraria SILVA [27], que observou uma pequena diminuição, embora não significativa, nos teores de sólidos solúveis durante todo o armazenamento do repolho minimamente processado armazenado a $5^{\circ} \mathrm{C}$, acondicionado em embalagens PEBD, PEAD e PP, justificando que este comportamento pode ter ocorrido, provavelmente, devido ao baixo metabolismo do produto na temperatura de $5^{\circ} \mathrm{C}$, associado com as altas concentrações de $\mathrm{CO}_{2}\left(0,8 \%\right.$ até o $5^{\circ}$ dia e chegando ao máximo de $3 \%$ no $7^{\circ}$ dia) no interior das embalagens, reduzindo os processos metabólicos e, conseqüentemente, o consumo das reservas celulares.

Observou-se redução do teor de vitamina $\mathrm{C}$ em todas as embalagens e temperaturas estudadas, sendo a maior na embalagem PET à $10^{\circ} \mathrm{C}$ (em torno de $\left.43 \%\right)$ no $6^{\circ}$ dia de armazenamento (Figura 3 b). A temperatura de $10^{\circ} \mathrm{C}$ proporcionou a maior redução de vitamina $\mathrm{C}$, enquanto que 0 e $5^{\circ} \mathrm{C}$ não diferiram estatisticamente entre si.

Na embalagem PVC, armazenada a $0^{\circ} \mathrm{C}$, ocorreu redução acentuada até o $3^{\circ}$ dia e, praticamente, não existindo alterações até o final do armazenamento. A $5^{\circ} \mathrm{C}$ não ocorreu redução significativa até o $3^{\circ}$ dia, sendo mais acentuada até o $6^{\circ}$, permanecendo praticamente constante até o final. Para $10^{\circ} \mathrm{C}$, as maiores reduções ocorreram até o $6^{\circ}$ dia de armazenamento permanecendo praticamente constante até o final do mesmo, porém apresentando valores sempre inferiores aos obtidos a 0 e $5^{\circ} \mathrm{C}$. Para a embalagem PET, a redução foi maior até o 6ํำ dia de armazenamento para as três temperaturas estudadas, sendo que também não houve diferença significativa entre 0 e $5^{\circ} \mathrm{C}$, diferenciando-se de $10^{\circ} \mathrm{C}$ que apresentou a maior redução de vitamina $\mathrm{C}$ durante todo o armazenamento. De maneira geral, o repolho acondicionado na embalagem PVC apresentou menor redução de vitamina C quando comparado com a embalagem PET, nas três temperaturas estudadas.
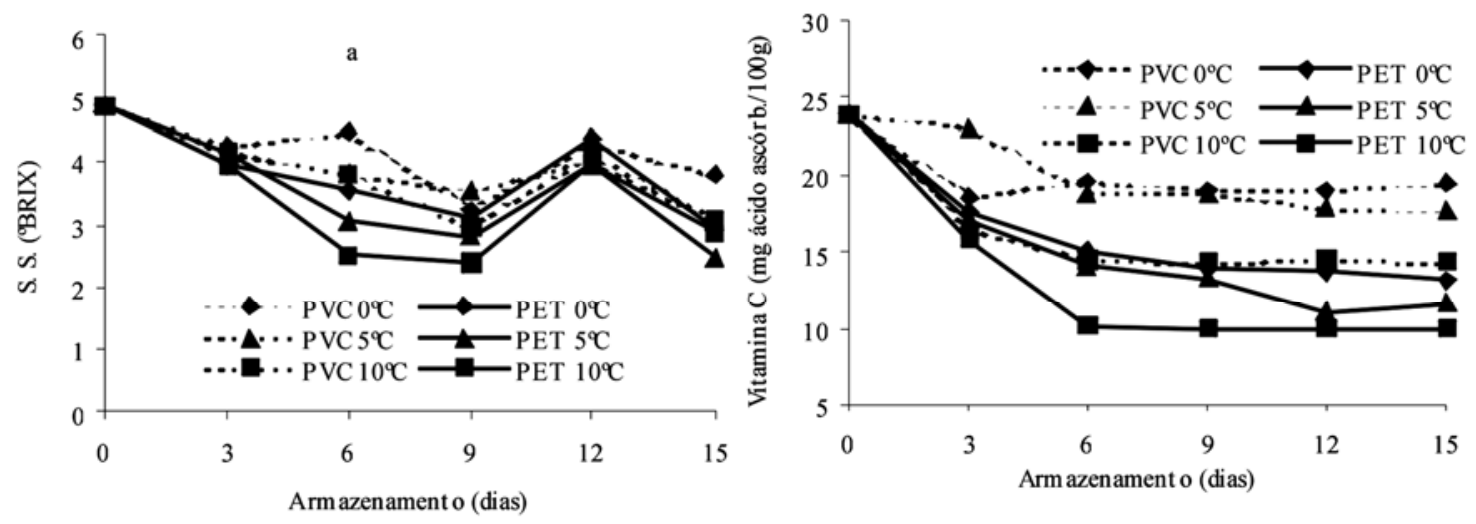

FIGURA 3 - Valores de sólidos solúveis (a) e vitamina C (b) durante o armazenamento de repolho minimamente processado 
Estes resultados não estão de acordo com SILVA [27], que observou redução nos teores de vitamina C somente no primeiro dia de armazenamento refrigerado, estabilizando-se após este periodo. No entanto, KLIEBER \& FRANKLIN [18] ao estudar o conteúdo de ácido ascórbico em repolho Chinês minimamente processado, concluíram que durante 11 dias de armazenamento a $4^{\circ} \mathrm{C}$ houve diminuição significativa. Segundo KLEIN [17], a redução de vitamina $\mathrm{C}$ está diretamente relacionada com o aumento da taxa respiratória, da evolução do etileno e com a descompartimentação celular, além dos fatores ambientais e genéticos, tais como calor, luz, $\mathrm{O}_{2}, \mathrm{pH}$, espécie e variedade cultivada.

\section{4 - CONCLUSÕES}

O filme de policloreto de vinila (PVC), $12 \mu \mathrm{m}$, garantiu melhores condições de conservação ao repolho minimamente processado quando comparado a embalagem plástica de tereftalato de polietileno-PET.

A embalagem de tereftalato de polietileno (PET), foi considerada como não adequada para o armazenamento de repolho minimamente processado, devido ao fato da mesma manter a concentração de $\mathrm{O}_{2}$ e $\mathrm{CO}_{2}$ em seu interior em valores idênticos ao da atmosfera.

Não verificou-se diferença significativa no período de conservação do repolho minimamente processado armazenado nas temperaturas de 0 e $5^{\circ} \mathrm{C}$, nas duas embalagens avaliadas. No entanto, a $10^{\circ} \mathrm{C}$ a vida útil do produto reduziu-se significativamente.

\section{5 - REFERÊNCIAS BIBLIOGRÁFICAS}

[1] BEM-ARIE, R.; BAZAK, H.; BLUMENFELD, A. Gibberellin delays harvest and prolongs life of persimmon fruits. Acta Horticulturae, Wageningen, v.179, p.807-814, 1986.

[2] BENEDETTI, B.C.; GOLINELI, C. C.; SARANTÓPOULOS, C.I.G.L. Avaliação de pimentão minimamente processado em rodelas e tiras, armazenado nas temperaturas de $5 \mathrm{e}$ 10oC. In: XVIII Congresso Brasileiro de Ciência e Tecnologia de Alimentos, Porto Alegre, RS. Anais, v.1, p.1241-1245, 2002.

[3] BOLIN, H.R. \& HUXSOLL, C.C. Effect of preparation procedures and storage parameters on quality retention of salad-cut lettuce. Journal of Food Science, v.56, n.1, p.60-67, 1991.

[4] BRECHT, J.K.; CHAU, K.V.; FONSECA, S.C.; OLIVEIRA, F.A.R.; SILVA, F.M.; NUNES, M.C.N.; BENDER, R.J. Maintaining optimal atmosphere conditions for fruits and vegetables throughout the postharvest handling chain. Postharvest Biology and Technology, v.27, p.87-101, 2003.

[5] CARVALHO, C.R.L.; MANTOVANI, D.M.B.; CARVALHO, P.R.N.; MORAES, R.M. Análises químicas de alimentos. Campinas: ITAL, 1990.

[6] Chitarra, M.I.F. \& CHITARRA, A.B. Pós-Colheita de Frutos e Hortaliças: Fisiologia e Manuseio, Lavras: ESAL FAEPE, 1990.
[7] CHITARRA, A.B. \& PRADO, M.E.T. Tecnologia e armazenamento pós-colheita para frutos e hortaliças in natura. Lavras: UFLA/FAEPE, 2002.

[8] CRISOSTO, C.H.; MITCHAM, E.J.; KADER, A.A. Recomendations for Maintaining Postharvest Quality. http:/ / postharvest.ucdavis.edu. 2000.

[9] DAREZZO, H.M. Determinação de composição gasosa e sistemas de embalagens adequadas para conservação de alface americana 'Lorca' minimamente processada. Campinas, SP, 2004, 155p. Tese (Doutor em Engenharia Agrícola), Faculdade de Engenharia Agrícola, Universidade Estadual de Campinas (UNICAMP).

[10] FERRI, V.C. Controle da maturação e conservação de caquis (Diospyrus kaki, L.) cultivar fuyu. Pelotas, 2000. 73p Tese (Doutor em Fitotecnia), Faculdade de Agronomia Eliseu Maciel, Universidade Federal de Pelotas (UFPEL).

[11] FREIRE; M.T..A \& REYES, F.G.R. A importância de polietileno tereftalato (PET) na indústria de embalagens para alimentos. Bol. SBCTA, 31(2): 129-136, jul/dez 1997.

[12] INSTITUTO ADOLFO LUTZ. Normas Analíticas do Instituto Adolfo Lutz: Métodos químicos e físicos para análise de alimentos. $2^{\circ}$ edição, São Paulo: Instituto Adolfo Lutz, v. 1, 1985. 371p.

[13] KADER, A.A. Biochemical and physiological basis for effects of controlled and modified atmospheres on fruits and vegetables. Food Technology, v. 40 p. 99-104, 1986.

[14] KADER, A.A. Recomendations for Maintaining Postharvest Quality. http://postharvest.ucdavis.edu. 2000.

[15] KASMIRE, R.F. \& CANTWELL, M. Postharvest handling systems: flower, leafy, and stem vegetables. In: KADER, A.A. (Ed.) Postharvest technology of horticultural crops. Oakland, California: University of California, 1992. Cap.30, p.267-270.

[16] KAYS, S.J. Postharvest physiology of perishable plant products. New York. Van Nostrand Reinhold, 1991. $532 \mathrm{p}$.

[17] KLEIN, B.P. Nutritional consequences of minimal processing of fruits and vegetables. Journal of Food Quality,v. 10, p. 179-193, 1987.

[18] KLIEBER, A. \& FRANKLIN, B. Ascorbic acid content of minimally processed chinese cabbage. Journal of the Science of Food and Agriculture. v. 81, p. 201-205, 1999.

[19] MARTH, E.H. Extended shelf life refrigerated foods: microbiological quality and safety. Food Technology, v. 52, p. 57-62, 1998.

[20] PEREIRA, L. M. Acondicionamento de goiabas minimamente processadas por desidratação osmótica em embalagens sob atmosfera modificada passiva. Campinas, SP 2002, 159p. Dissertação (Mestre em Engenharia de Alimentos), Faculdade de Engenharia de Alimentos, Universidade Estadual de Campinas (UNICAMP).

[21] RINALDI, M.M. Conservação de repolho minimamente 
processado em diferentes sistemas de embalagem. Campinas, SP, 2005, 110p. Tese (Doutor em Engenharia Agrícola), Faculdade de Engenharia Agrícola, Universidade Estadual de Campinas (UNICAMP).

[22] ROURA, S.I.; DAVIDOVICH, L.A.; DEL VALLE, C.E. Quality loss in minimally processed swiss chard related to amount of damaged area. Lebensm-Wiss und Technology, v.23, n.1, p.53-59, 2000.

[23] SARANTÓPOUlOS, C.I.G.L., AlVES, R.V., OLIVEIRA, L.M., GOMES, T. Embalagens com atmosfera modificada. Campinas: CETEA/ITAL, 1998. 114p.

[24] SARANTÓPOULOS, C.I.G.L.; OlIVEIRA, L.M.; TELES, C.S.; COPPELMANS, S.A. Efeitos da embalagem e da temperatura de estocagem na qualidade de couve minimamente processada. Brazilian Journal of Food Technology, v.6, n.2, p.185-190, 2003.

[25] SCHLIMME, D.V. Marketing lightly processed fruits and vegetables. HortScience, v. 30, p. 15-17, 1995.

[26] SENTER, S.D.; CHAPMAN, G.W.; FORBUS, W.R.; PAYNE, J.A. Sugar and non-volatile acid composition of persimmons during maturation. Journal of Food Science, Chicago, n. 56, p. 989-991, 1991.
[27] SILVA, E.O. Fisiologia pós-colheita de repolho (Brassica oleracea cv. Capitata) minimamente processado. Viçosa, MG, 2001, 90p. Tese (Doutor em Fisiologia Vegetal) Departamento de Biologia, Universidade Federal de Viçosa (UFV).

[28] SILVA, V.V.; SOARES e GERALDINE. Efeito da embalagem e temperatura de estocagem na conservação de mandioca minimamente processada. Brazilian Journal of Food Technology, v.6, n.2, p. 197-202, 2003.

[29] SUSLOW, T.V. \& CANTWELL, M. Recomendations for Maintaining Postharvest Quality. http:/ / postharvest.ucdavis.edu. 2000.

[30] WILLS, R.B.H.; LEE, T.H.; GRAHAM, D.; McGLASSON, W.B.; HALL, E.G. Postharvest: an introduction to the physiology and handling of fruit and vegetables. Austrália: New South Wales University Press, 1981.

\section{6 - AGRADECIMENTOS}

À Fundação de Amparo à Pesquisa do Estado de São Paulo e à Pós-Graduação da Faculdade de Engenharia Agrícola da UNICAMP pelos auxilios concedidos. 